\title{
ReqPriSec: Security and Privacy aware Web-based Versatile Requirement Engineering Tool
}

\author{
Tejas Shah \\ Department of ICT \\ Veer Narmad South Gujarat University \\ Surat, India
}

\author{
S. V. Patel \\ Veer Narmad South Gujarat University \\ Surat, India
}

\begin{abstract}
Requirement Engineering is the process of eliciting, analysing, negotiating, specifying and managing functional and non functional requirements of a system. The RE phase faces some challenges like managing ambiguous, incomplete and inconsistent requirements; specifying requirements in unstructured format; inefficient elicitation of requirements from stakeholders and managing various artefacts of requirements along with non functional requirements. These challenges may arise in any software development methodologies and may hinder the progress of project and system development. The security and privacy requirements have not given much attention in RE. There is a strong need of versatile and security-privacy aware RE tool to elicit, manage and specify requirement efficiently and in standardized format. This paper proposes a unique, securityprivacy aware "ReqPriSec" tool to manage and store the requirements in objective manner without major efforts of natural language requirement statements. The "ReqPriSec" tool is tested and evaluated based on different parameters on E-voting case study.
\end{abstract}

\section{Keywords}

Requirement Engineering, Non Functional Requirement, RE tool, Security Requirements, Privacy Requirements

\section{INTRODUCTION}

Requirement Engineering (RE) is one of the important and inherent branches of SE which integrates and holds all the phases of SE tightly together. RE is the systematic and diligent procedure of eliciting, elaborating, analysing, prioritizing, modelling and specifying requirements of a system. The detailed, approved requirements are documented and specified as the basis for design and development of a system. RE is considered to be critical and complex process within the software intensive systems development [1] [2] [3]. It is critical and complex; firstly critical because the quality of the systems is strongly affected by the quality of the requirements and complex as it demands the fine grain level domain detail from diverse set of stakeholders. Many errors can originate from requirement phase, caused by ambiguous, missed, incomplete and inadequate requirements leading to major delays, cost overruns in a project.

The growing web based applications, development of IoT, and evolvement of business processes requires security and privacy requirement notions to be incorporated in RE phases. The non-functional requirement is solution requirement describing the characteristics that customer want the system to have. Generally, Functional requirements define what a system should do and non - functional requirements define how a system should be. A subset of NFR domains, security and privacy are having profound significance for the web based applications. Information security is the practice of preventing unauthorized access, use, disclosure, disruption, modification, inspection, recording or destruction of information. The authentication and authorization property is also the subset of security; however it can be part of privacy also. Information security's primary focus is the balanced protection of the confidentiality, integrity and availability of data.

Privacy is the claim of individuals, groups, or institutions for themselves when, how, and to what extent information about them is communicated and transmitted to others. With enormous use of the internet, more personally identifiable information are electronically transmitted and disseminated lacking proper privacy protection mechanisms and tools. Therefore, the need for a methodology that considers and safe guards the privacy requirements is immense. Privacy assures that Personally Identifiable Information (PII) is collected, processed (used), protected and destroyed legally and fairly.

The traditional approach of Requirement elicitation, specification and modelling is time-consuming, expensive and difficult; and resultant specification typically becomes inconsistent, incomplete, ambiguous and rigid to trace [4] [5] [6]. The requirements in textual form are difficult to process or it requires the NLP support. Therefore, it is advisable to have a new approach with structured requirement specification format to manage the requirement repositories in an efficient manner. The RE tool shall be developed which provides facilities of managing requirements of system efficiently. There are plenty of commercial tool available in the category of RE tool, RM tool, BA tool and agile tool. We have studied some of the database of Requirement Management tool and analysed some of the tools which falls in major category suitable for waterfall and agile based software development methodology. Some of the common features of RE tool are mentioned below.

\section{Common Features of RE Tools:}

- GUI based environment for Requirement elicitation, management and analysis

- Hierarchical management of requirements from project level to sub system and Functional requirement level

- Requirement Change management and version control

- Traceability of requirements

- $\quad$ Requirement modelling with Use case support

- Requirement Prioritization

- Central repository to manage the requirement

- Support of either waterfall or agile methodology

- Role based access control for accessing requirement modules 
- Import and export requirement from various sources

This paper demonstrate the proposed tool "ReqPriSec" to elicit, manage and specify functional, security and privacy requirements of system efficiently with standardized specification format.

The rest of the paper is organized as follows. Section II covers review of literature of various open source RE tools with their features. The "ReqPriSec" tool development and features are described in Section III. The evaluation and results of proposed tool along with few open source tools are covered in Section IV. The last section concludes the work with future direction.

\section{LITERATURE REVIEW}

This section covers literature study of various open sources RE tools available from web resources. Current RE tools' capabilities [7] and the ISO TR 24766 [8] have been taken into account to review the tools available in the industry. Carrillo de Gea et al. in [9] conducted study to get insights of how current RE tools adapt to RE activities and assess tool features in three concrete scenarios. This technical report provides guidance and insights on desirable capabilities of RE tools. It supplements ISO/IEC 14102:2008, Information technology - Guideline for the evaluation and selection of CASE tools, which details a set of evaluation criteria for CASE tools without referencing a specific activity or services. We have analysed some of the open source RE tools to analyse the features and for further evaluation and comparison.

\subsection{Open Source RE Tools}

\subsubsection{ReqHeap}

Requirement Heap is a web based open source requirement management tool[10], which allows user to enter requirement in rich text, supports versioning and the management of requirements. It also handles use cases, interviews and test cases for multiple projects. The database repository is in MySQL and the interface is developed through PHP technology. Role based access control is provided for the users of tool. Requirements can be exported in PDF, XLS and in CSV file format. Test cases and releases can be added to plan final releases.

\subsubsection{Rmtoo}

The rmtoo is a free and open source requirements management tool works in command line to handle the requirements [11]. The development environment of tool can handle the input and output files. The revision control system of tool can handle different revisions, baselining, tagging, branching and many other things extremely well. The analytics module features the heuristics to evaluate the quality of requirements. All the artefacts of SCRUM are supported in the tool. However, rmtoo is lacking GUI and database backend support.

\subsubsection{OSRMT}

The "Open Source Requirement Management Tool" is a platform independent tool [12] designed to achieve full SDLC support with traceability for features, requirements, design, implementation and testing. The interactive interface for requirements derivation, version control, attributes is supplemented with swing/J2EE. The web client is used to browse and edit artefacts in the tree of requirements, features and design. The tool provides full traceability, versioning, hierarchal organization, custom reports and a change control module. The centralized database repository is used to manage all the requirements.

\subsubsection{Modelio}

Modelio is GUI based open source requirement and business process modelling tool [13]. Modelio provides a modeling environment, supporting a wide range of models and diagrams, and providing model assistance and consistency checking features. This tool combines BPMN support and UML support. The java designer module is used to generate java code and reverse for javadoc generation. The tool also provides additional modules like java designer, XSD designer, WSDL designer, TOGAF architect and SysML architect. Another tool of modelio family is modelio analyst which is created for analysis of requirements, risks and goals. This tool is also supporting graphical requirement modelling with SysML standard with impact analysis, traceability of requirements and import/export facility.

\subsection{Analysis of Key Features of Open Source RE Tools}

There are various features provided by the commercial and open source RE tools. For the comparison we have taken key features like web based/desktop based support, UML support, baseline and versioning, tracing, NFR support and access control facility. The analysis is completed in two tables. Table 1 analyses these features.

Table 1. Analysis of Features of RE Tools

\begin{tabular}{|c|c|c|c|c|}
\hline Features/Tool Name & ReqHeap & OSRMT & rmtoo & Modelio \\
\hline Web based/Desktop based & Web based & $\begin{array}{c}\text { Console and } \\
\text { desktop based }\end{array}$ & Console based & Web based \\
\hline UML Support & Yes & No & $\begin{array}{c}\text { Requirement } \\
\text { diagram }\end{array}$ & Yes \\
\hline Baseline and Version & Yes & Yes & Yes & Yes \\
\hline Tracing & Yes & Yes & Yes \\
\hline NFR Support & No & No & No & Yes \\
\hline Access Control & Yes & No & Yes & Yes \\
\hline
\end{tabular}




\begin{tabular}{|c|c|c|c|c|} 
Agile/ Waterfall Method & Waterfall & Waterfall & $\begin{array}{c}\text { Waterfall and } \\
\text { Agile both }\end{array}$ & $\begin{array}{c}\text { Waterfall and Agile } \\
\text { both }\end{array}$ \\
\hline NLP & No & No & $\begin{array}{c}\text { Parsing of } \\
\text { requirements }\end{array}$ & Yes \\
\hline Data Exchange Standard & No & No & No & Yes, XML and SysML \\
\hline On Cloud & No & No & No & No \\
\hline Central Repository & Yes & Yes & No & Yes \\
\hline
\end{tabular}

The above table analyses the key features of tools like web based or desktop based system, UML support, NFR and access control provision, requirement tracing, methodology supported, NLP inclusion, data exchange standard, use of central repository and cloud based access and version control. It is noticed that Requirement traceability and version control are supported by most of the tools to manage and analyse the requirements. To support the intra-net based system, so many tools are web based and few tools are console based for desktop system. The key point is the support of NFR, which is missing in almost all the tools. For traceability and version control different techniques are used like matrix, table or tree based hierarchy.

It is to be noticed that tools are available for agile and traditional software development life cycle. Many tools are providing hosting facility on cloud or on premise support. But only few tools are supporting standardized common requirement exchange format. It is observed that linking of functional and non functional requirements are not implemented in many tools. In the open source tool category modelio tool supports all the key features of requirement analysis and management. However, the security and privacy requirement support is not present in the tool fully.

There are significant numbers of RE tools quickly evolving with the business requirements. The demand for flexibility, lean and agile development, worldwide collaboration, and requirements and other non functional requirements. There are many other tables which manage the requirements artefacts, role based access control, actor data and linking of FR and NFR. The interactive user interface is designed as a part of proposed tool to elicit the requirements from customers. To elicit the requirements with assistance of business analyst, several combinations of techniques like traditional, cognitive and modern elicitation techniques have been used in the $1 \mathrm{st}$ layer. These techniques shall be used to extend and redesign the proposed tool depending on the application.

\section{- Prototyping}

The requirement engineer and business analyst are taking continuous response/feedback from customers in designing the novel GUI interface of the proposed REQPriSec tool development. With prototyping technique the framework is allowing the customers to design and add their additional non functional requirement list.

\section{- Use cases}

This technique intends at defining the requirements by portraying complete flow of events to the stakeholders in the form of a story telling style. Instead of processing large text, we used the form based collection of main flow and alternative flow of the functional requirement. This layer also includes the facility of linking use cases with the functional advanced software ecosystems is changing the RE tool development process. The RE process seems to be well covered by current RE tools, but there is still a certain perimeter for enrichment, principally with regard to requirements modelling, open data format and data integration features. The available tools in market might not adequately support the phases and activities of RE process in absence of certain features like incorporation of non functional requirements and artefacts of the requirements. There is a storing need of standardized, web-based, NFR agnostic requirement engineering tool.

\section{DESIGN and IMPLEMENTATION of TOOL}

\subsection{Tool Database and Elicitation Methods}

The proposed "ReqPriSec" tool has support of relational database and specifications are also stored in relational tables. The initial process of the RE tool requires the design of relational database to include project details, functional requirements, non-functional requirements, security and privacy properties with artefacts. The integration of project detail and linking it with its sub systems and hierarchy of nested functional requirements need to be elicited and analyzed. Relational model is created for mapping project requirements, functional requirements, ER modelling, narrative use case, security requirements, privacy requirement and hence providing the validation with stakeholders.

\section{- Questionnaire}

The questionnaire is a method of requirement elicitation which is simple and requires lesser time and cost. To get the precise results, we have used clear, concise and structured set of options to obtain genuine requirements with set of options and choices provided for metadata as well as security, privacy and other NFR attributes.

\section{- Form Based Elicitation}

The GUI based interactive forms are created for requirement elicitation. The forms based elicitation garners the process of collecting requirements and giving aesthetics to customers of what is to be specified. The interactive and extendable interface is designed in the framework which gathers information about project, task, and work practices of requirements, artefacts of requirements, NFR and other linkages. This elicitation interface forms the pattern of submit/response style which provides more customer involvement.

\subsection{Technology and Deployment of Tool}

To implement the tool NetBeans IDE Version 8.2 has been selected for the development and maintenance. The tool is using other open source technologies like JSP, Servlets, XML, Web Services, XML Schema, DOM parser and many alike. 
The tool is deployed on the GlassFish server 4.1.1. The services are also deployed on the same server. To create and operate the database MySQL as a part of WAMP Server is utilized. tool. The tool has taken 2021 milliseconds for deployment on GlassFish server. This time is may vary depending on system's configuration. The server is running and taking the request with HTTP listener on port 36305.

Figure 1 shows the screenshot of deployment of "ReqPriSec"

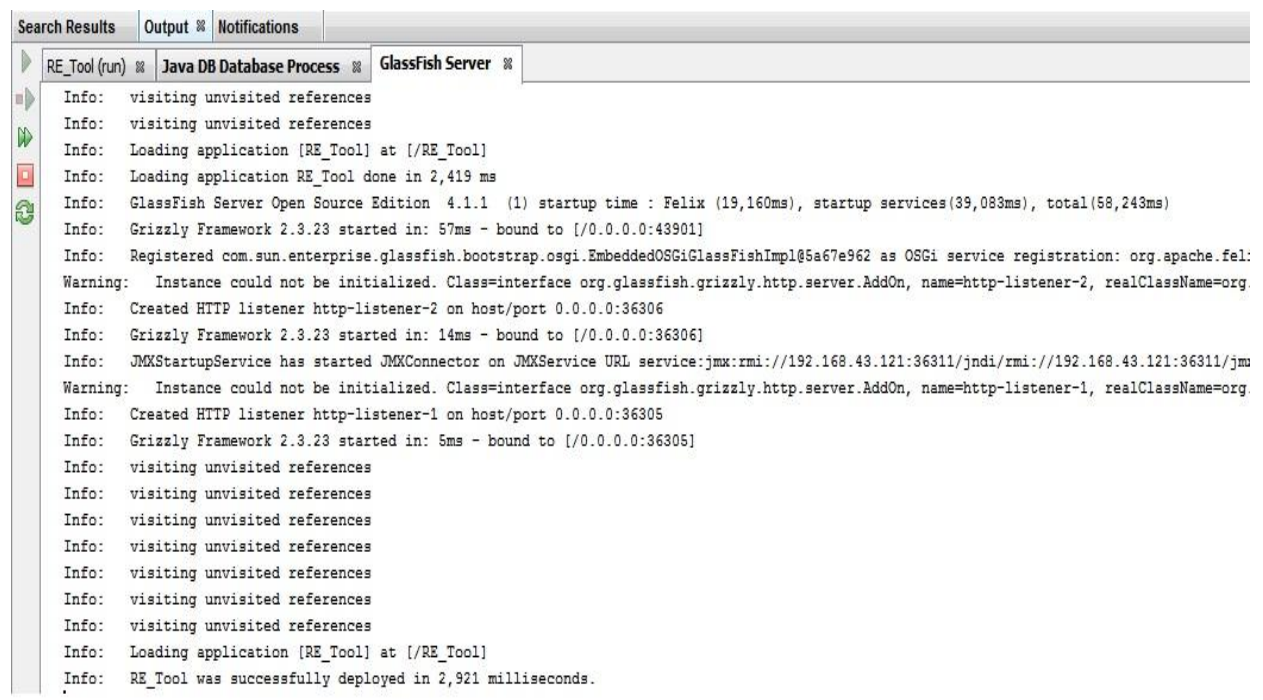

Fig 1: Deployment of ReqPriSec Tool

\subsection{Features and Layout of Proposed "ReqPriSec" Tool}

This section shows the unique features of the proposed tool with basic screen layout of the interface and hierarchy of requirement components for managing the requirements. The proposed tool is supported so many features which are described in result section. The prominent and salient technical features of tool includes open source development, web based interactive interface, web services orientation, extensible and customizable module of security-privacy properties.

\subsubsection{Project Detail}

The project wise requirement management gives better insights and grouping to filter the requirements of system. The starting point of the tool is the project management and it takes basic detail of the project like scope, objective, type, assumption and schedule as shown in Figure 2. The "ReqPriSec" tool is not created for in-depth project management and hence there is only one module designed for project which is linked with requirement and other modules.

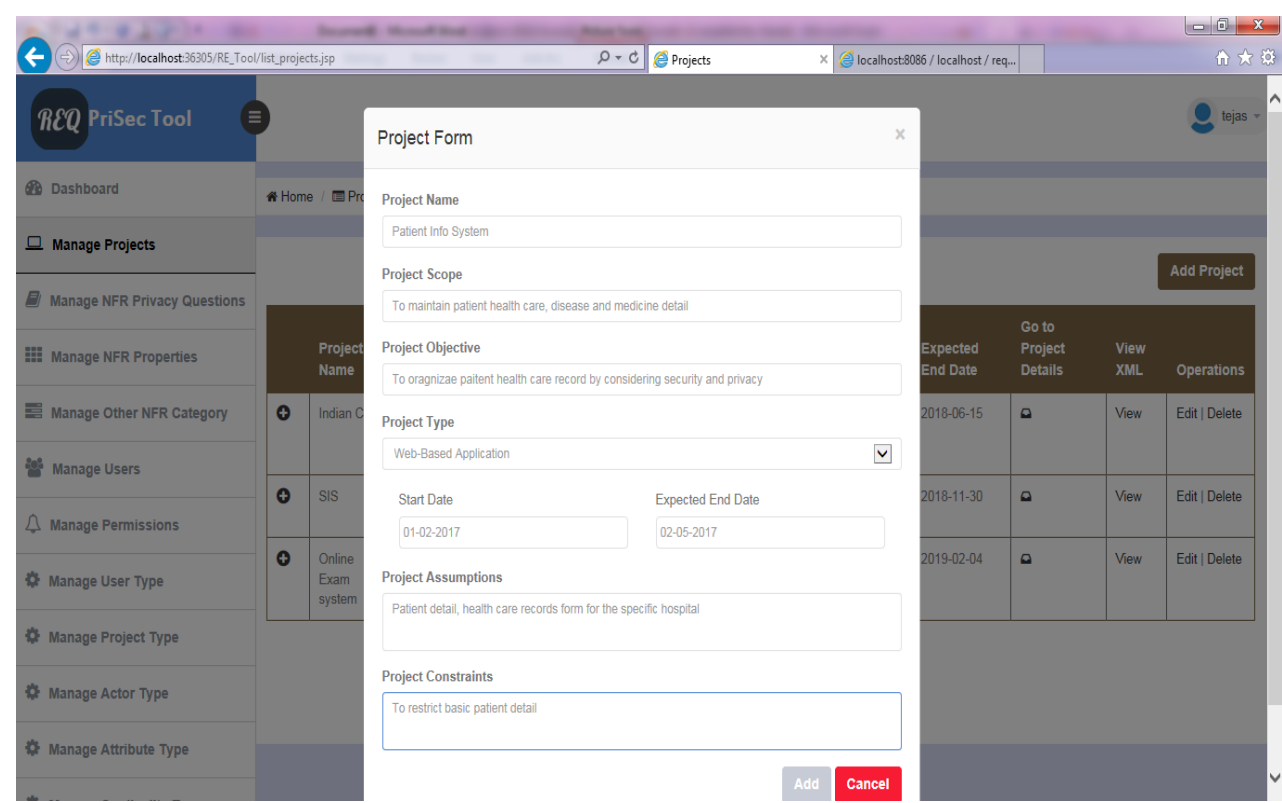

Fig 2: Project Interface 


\subsubsection{Requirement Lifecycle Coverage}

The proposed, state-of-art RE tool provides an integral support to all the RE phases including Requirement elicitation, analysis, prioritization, management and Requirement Specification in systematic manner. The initial phase of project management also coves the main properties of project. The requirements are elicited, analysed, negotiated, managed and specified in different modules of this tool. The Figure 3 shows the image of functional requirement module.

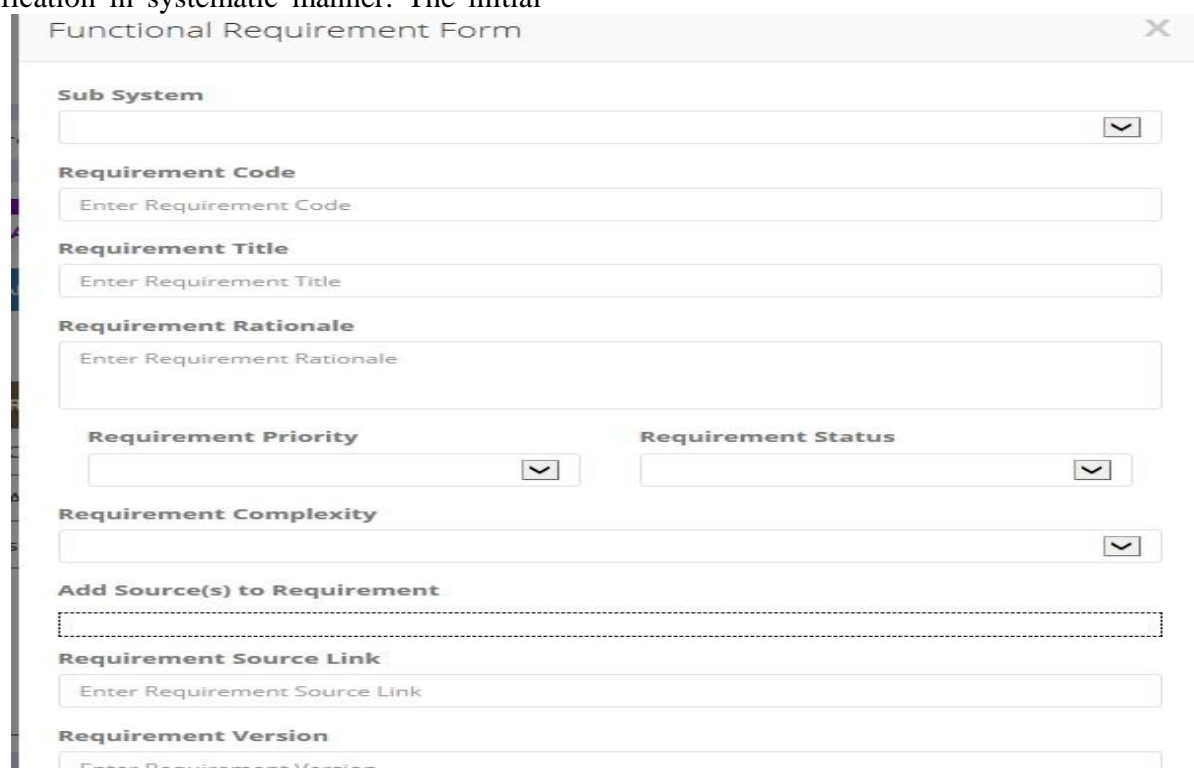

Fig 3: Functional Requirement Interface

\subsubsection{Customizable and Extendable NFR}

\section{Properties}

This tool is customizable to add and manage different NFR properties by the user's choice. It allows the customer to add, modify and update the nested properties of security and privacy depending on the domain and their interest. The properties of security and privacy can be extended with this tool and user can manage multiple levels of nested options. The Figure 4 shows the property category and sub options which can be extended very easily.

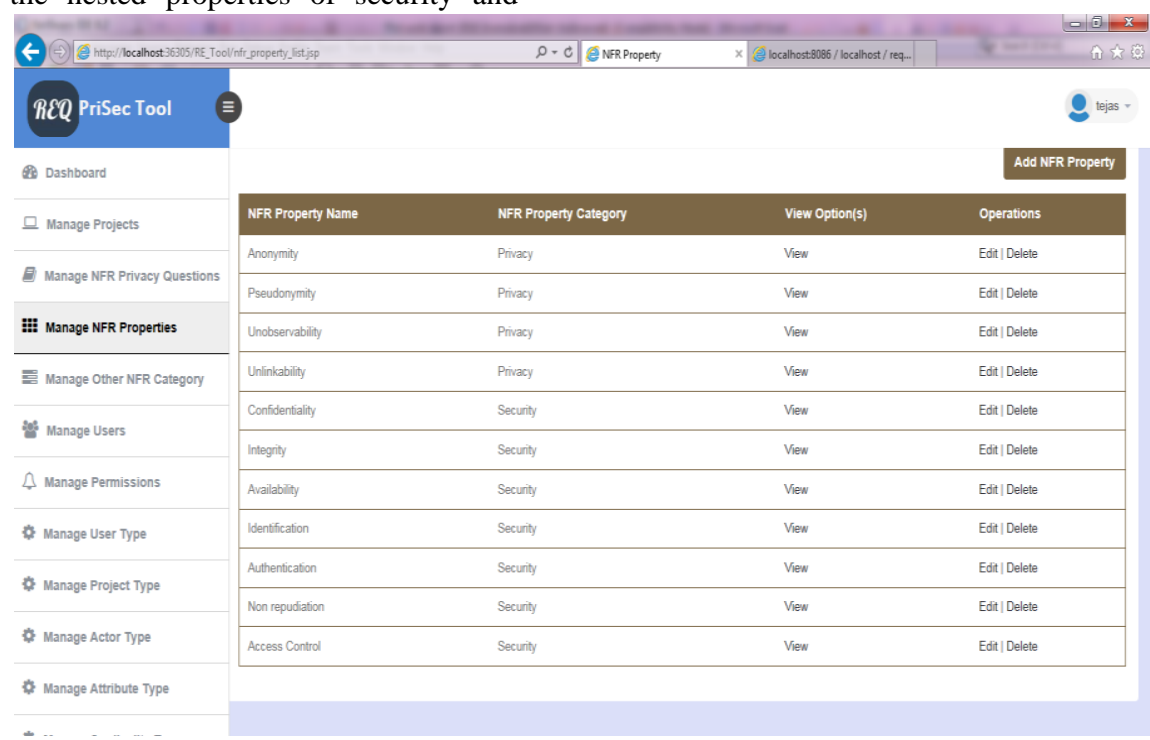

Fig 4: Interface of Sub Properties of Security, Privacy

\subsubsection{Requirement Artefacts Management}

It is also important to collect the artefacts and metadata of the requirements. This metadata helps the business analyst, designer to easily trace, manage the different version, priority and complexity of the requirements. The artefacts and properties of the requirement specification is also the unique feature of the tool.

\subsubsection{Requirement Exchange with Interoperable Format}

The tool has the support of the RDM language which is used to validate the XML artefacts generated from the tool. To exchange the requirements in intra-inter organization is quite easy, as requirements are specified in standardized and interoperable format. The re-import and retrieval of existing requirements are possible with SQL data records. The "ReqPriSec" tool can support various format for communicating and exchanging requirements of the project. 


\subsubsection{Strong Elicitation}

Most of the errors in system development stem from the incomplete, ambiguous, poorly written, inconsistent, erroneous, inappropriate, missing requirements. In this tool, the business analyst elicits the requirements from customers with powerful elicitation interface. The tool's interface is user-friendly, customer oriented and elegant for eliciting the key requirements. The interface has not too much textual components and hence it will prevent time consuming natural language processing. The interface of "ReqPriSec" is taking proactive approach in error detection and correction. The visualization of the tool provides clarity and quality to the requirement analysis process also.

\subsubsection{Requirement Prioritization}

The tool offers systematic and simple way of documenting, analysing and prioritizing the requirements. The priorities of the requirements are managed easily through user interface where customer can simply up-down the requirement content to change the priority. The Figure 5 shows the layout of managing prioritization.

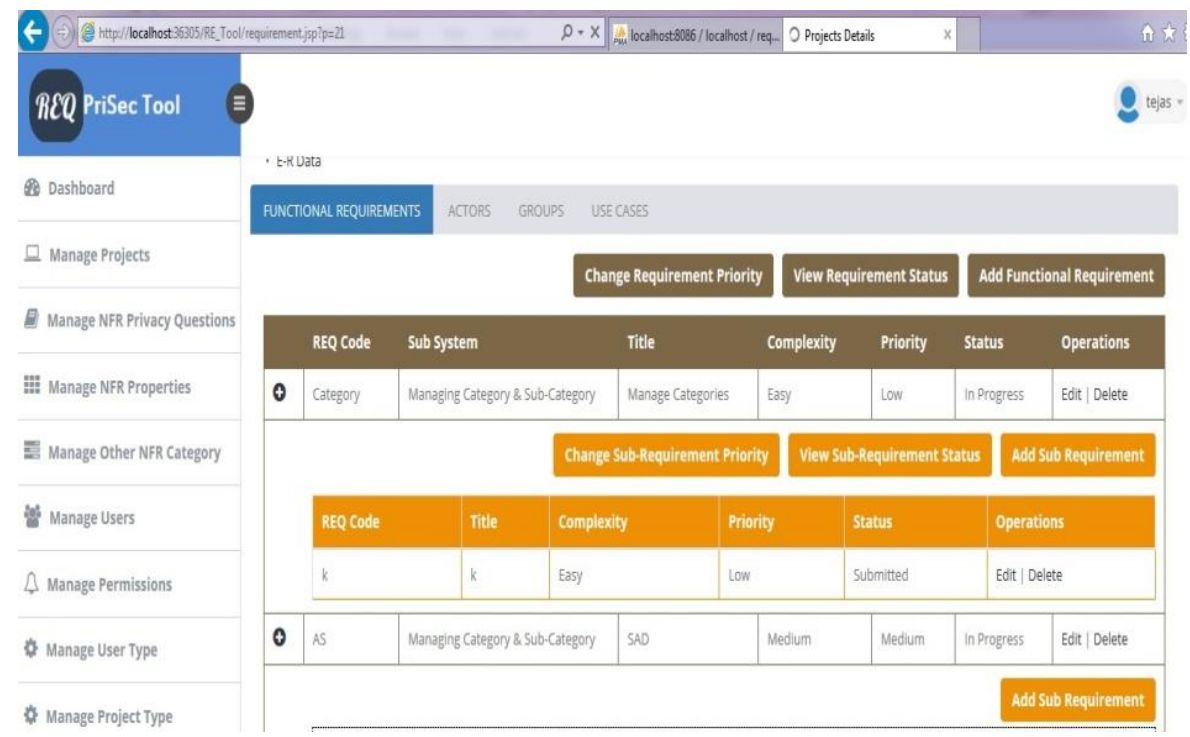

Fig 5: Interface of Requirement Prioritization, Status

\subsubsection{Requirement Modelling with Use Case}

One of the best ways to capture the goals of system is to model the requirement context with use cases. The graphical representation of use case is proven best for modelling requirements, but it requires complex graphical processing.
The tool has a support of describing the use cases in narrative manner. The basic flow and alternative flow of the scenario is also represented as the requirement feature as shown in Figure 6.

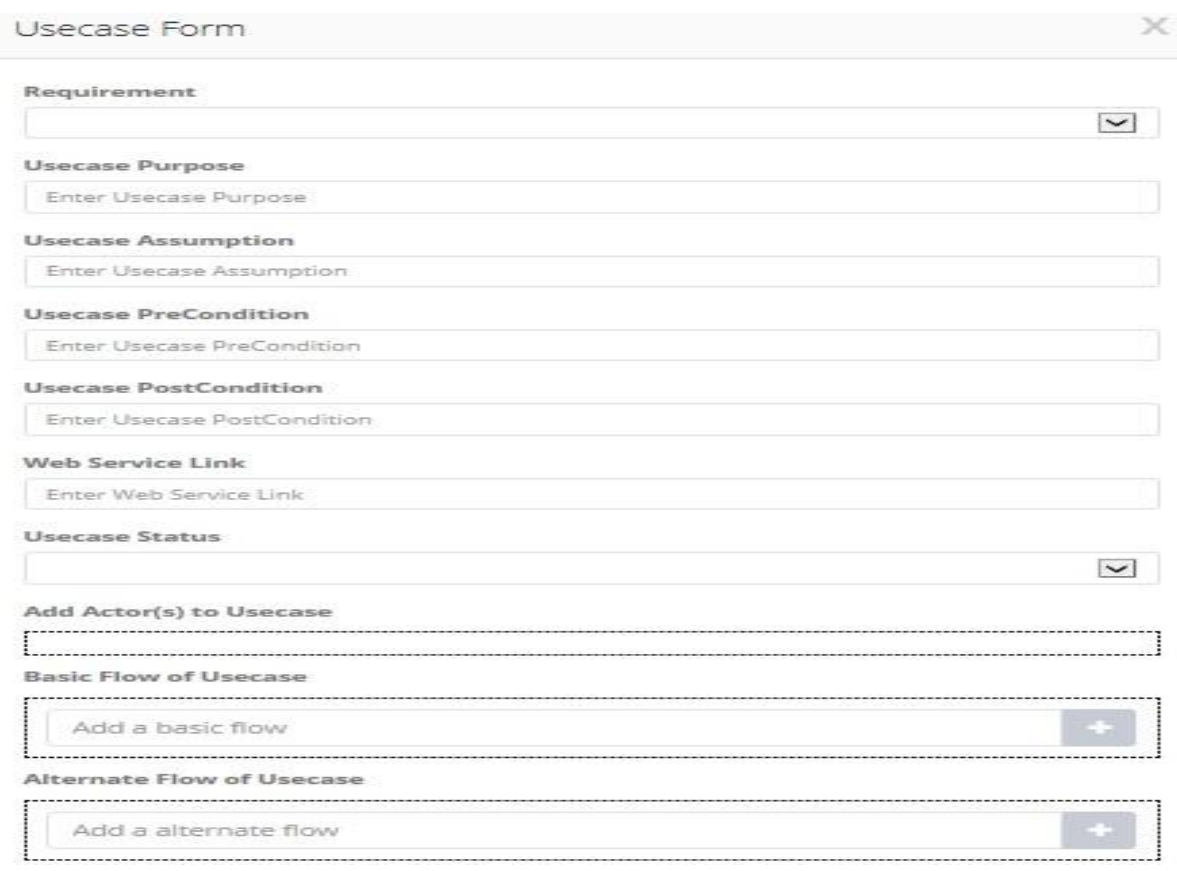

Fig 6: Interface of Use Case Form 


\subsubsection{Managing Security and Privacy Requirements}

The key features of the framework are implemented with interactive and objective based interface. As per the design of taxonomy described in Chapter 4, security and privacy are managed at functional requirement level and system level also. The business analyst will guide the customer for specifying their security and privacy options for the related requirements. This linking is shown in Figure 7 and 8

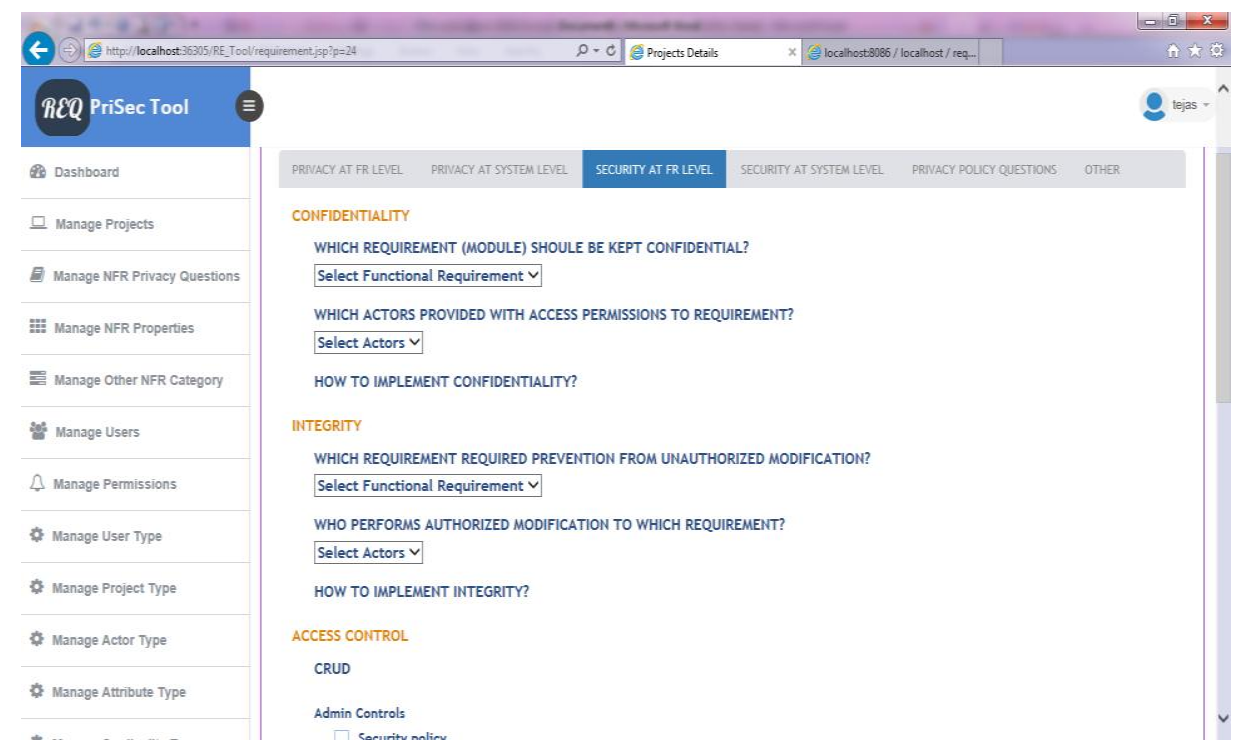

Fig 7: Interface of Security at FR Level

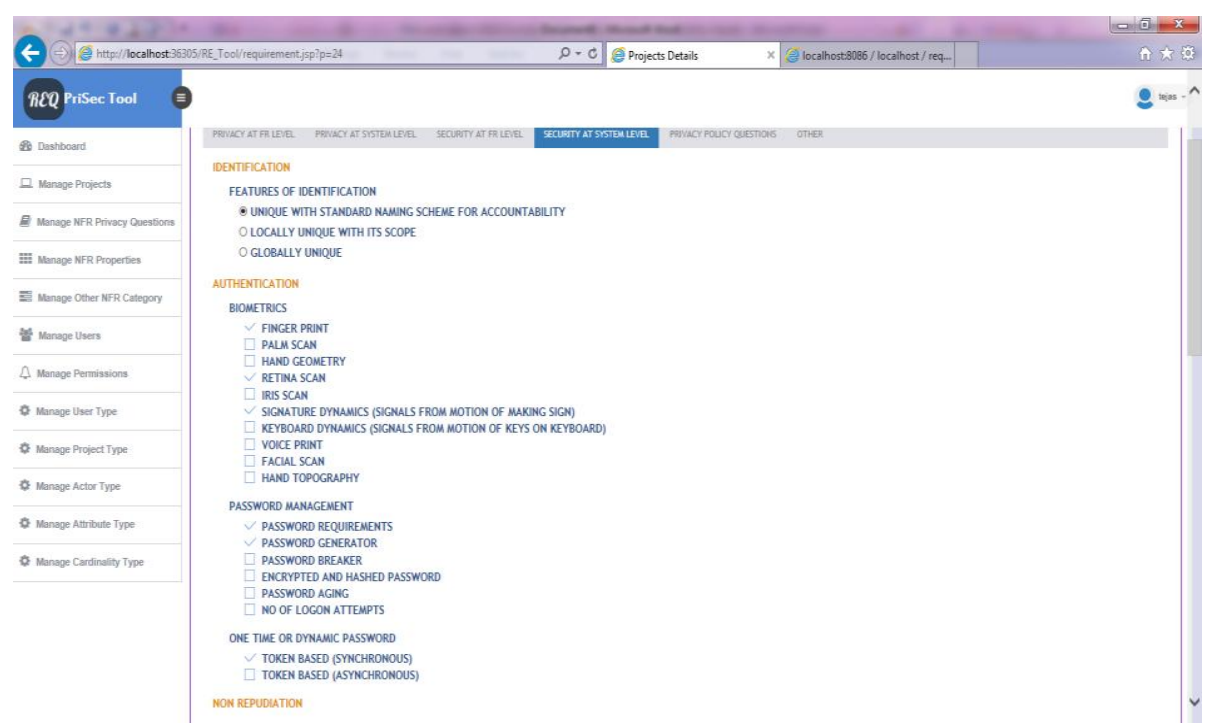

Fig 8: Interface of Security at System Level

\section{EVALUATION and RESULT}

This section includes the evaluation and testing results with different parameters. First section covers feature matrix which is designed from ISO/IEC TR 24766 standard. This new feature matrix is applied for comparison with four open source RE tools. The next section evaluates the tool to test result by considering case study of E-voting system.

\subsection{Feature Matrix Based Comparison}

\subsubsection{Feature Matrix for Comparison}

There are different feature matrices available in the literature for Requirement Engineering tool evaluation. A 113-feature list with count matrix is created by considering following framework and papers to analyse and evaluate proposed REQPriSec tool with other RE tools. The ISO/IEC TR
24766:2009 is a framework for assessing RE tools' capabilities [8]. The other white paper by Seilevel research evaluated different tools based on selected features [14]. The survey of capabilities of RE tools included 126 features from different categories [9].

The category and sub categories are formed on the basis of requirement elicitation, prioritization, analysis, traceability and non functional requirements specifically with security and privacy features. We have taken few open source RE tools for comparison with our REQPriSec tool. The category and sub categories comprises of Project, Requirement Elicitation, Requirement Analysis, Prioritization, Traceability, Specification, Requirement Architecture, Management, Modelling, NFR, Security, Privacy, Other tool features. The designed feature matrix is shown in Table 2. 
- RE Tool Feature Matrix

Table 2. RE Tool Feature Matrix

\begin{tabular}{|c|c|c|}
\hline Sub Category & \multicolumn{2}{|c|}{ Features } \\
\hline \multirow[t]{6}{*}{ Project } & \multicolumn{2}{|c|}{ Does tool collects project detail like project name (system name), project type, duration and budget? } \\
\hline & Project scheduling and tracking facility & $\begin{array}{l}\text { Tool manages functional and non functional } \\
\text { requirement of different project }\end{array}$ \\
\hline & $\begin{array}{c}\text { Managing project sub systems, requirement specific } \\
\text { to project }\end{array}$ & $\begin{array}{l}\text { Review of various phase of system development life } \\
\text { cycle }\end{array}$ \\
\hline & $\begin{array}{l}\text { User management of the project (Actors of the } \\
\text { Project) }\end{array}$ & Project tracking with gnatt chart or related architecture \\
\hline & Facility of project risk and risk planning & $\begin{array}{l}\text { Defining stakeholders and roles of them for project } \\
\text { (system) }\end{array}$ \\
\hline & Project progress status display in dashboard & $\begin{array}{l}\text { Project, System and Requirement linking } \\
\text { (Requirements of a specific system) }\end{array}$ \\
\hline \multirow[t]{5}{*}{ Elicitation } & $\begin{array}{l}\text { Efficient and easy requirement collection and } \\
\text { gathering }\end{array}$ & $\begin{array}{l}\text { Gathering and managing different source of } \\
\text { requirements (e.g meeting minutes, interview } \\
\text { summary, questionnaire summary, RE workshop) }\end{array}$ \\
\hline & Creation of Unique ID for each requirement & $\begin{array}{c}\text { Input of requirement attributes like ReqName, Type, } \\
\text { Version, Status }\end{array}$ \\
\hline & Rich text formatting of requirements & $\begin{array}{l}\text { Importing requirements from multiple heterogeneous } \\
\text { format }\end{array}$ \\
\hline & $\begin{array}{l}\text { Spelling and grammar checking facility for } \\
\text { requirements }\end{array}$ & $\begin{array}{l}\text { Importing requirements from compatible format such } \\
\text { as ReqIF }\end{array}$ \\
\hline & $\begin{array}{l}\text { Automatic or semi-automatic way of requirement } \\
\text { gathering }\end{array}$ & $\begin{array}{l}\text { Support of elicitation templates and checklists before } \\
\text { gathering requirement }\end{array}$ \\
\hline \multirow[t]{4}{*}{ Analysis } & $\begin{array}{l}\text { Creating and comparing baselines of the requirement } \\
\text { (Versions) }\end{array}$ & $\begin{array}{c}\text { Tool is having feature of reporting bug and issues of } \\
\text { requirements }\end{array}$ \\
\hline & $\begin{array}{c}\text { Metrics and chart display for various requirement } \\
\text { attributes like status, priority (e.g. Showing in } \\
\text { different colour) }\end{array}$ & History of a requirements changes is easy to view \\
\hline & $\begin{array}{c}\text { Navigation from higher level of requirement to } \\
\text { lower level requirement, Decomposing higher level } \\
\text { requirement into detail }\end{array}$ & $\begin{array}{c}\text { Determining unclear, incomplete, ambiguous or } \\
\text { contradictory requirements and resolving all these } \\
\text { issues }\end{array}$ \\
\hline & $\begin{array}{l}\text { Rollback and undo of version of the requirement } \\
\text { (Working of previous version of the requirement) }\end{array}$ & $\begin{array}{l}\text { Analysis of technical, economical, operational } \\
\text { feasibility to implement the requirement }\end{array}$ \\
\hline \multirow[t]{2}{*}{ Prioritization } & $\begin{array}{l}\text { Requirement priority at the time of elicitation and } \\
\text { modification facility }\end{array}$ & $\begin{array}{l}\text { Navigation of requirements based on priority (Up and } \\
\text { down in menu) }\end{array}$ \\
\hline & Voting on requirements for setting priorities & $\begin{array}{l}\text { Deciding priority of requirements based on the } \\
\text { business or project objectives }\end{array}$ \\
\hline \multirow[t]{4}{*}{ Traceability } & $\begin{array}{l}\text { Linking of requirements to other requirements of the } \\
\text { same project. Dependency between requirements } \\
\text { (Parent and child requirement) }\end{array}$ & $\begin{array}{l}\text { Managing lifecycle of requirement. Creating and } \\
\text { editing flow in requirement flow diagram or } \\
\text { requirement dependency diagram if present }\end{array}$ \\
\hline & $\begin{array}{c}\text { Traceability analysis to identify inconsistent } \\
\text { requirement and missing links within the } \\
\text { requirements (e.g., FR which are not linked to a use } \\
\text { case) }\end{array}$ & $\begin{array}{l}\text { Verification of requirement: The tool should provide } \\
\text { the ability to document that the requirement was } \\
\text { fulfilled, how it was done, and who was responsible. }\end{array}$ \\
\hline & $\begin{array}{l}\text { Results of Traceability analysis in tree or table (How } \\
\text { many requirements are modelled to use case) }\end{array}$ & $\begin{array}{l}\text { The RE tool supports bi-directional tracing of } \\
\text { requirements. Parent to child requirements mapping or } \\
\text { requirement to design elements mapping }\end{array}$ \\
\hline & $\begin{array}{l}\text { Storing and managing the identification and } \\
\text { documentation of stakeholders and their roles and } \\
\text { responsibilities towards requirements }\end{array}$ & $\begin{array}{l}\text { Generating a report for missing and/or orphan } \\
\text { requirements. Facility of traceability matrix }\end{array}$ \\
\hline
\end{tabular}




\begin{tabular}{|c|c|c|}
\hline Sub Category & \multicolumn{2}{|c|}{ Features } \\
\hline \multirow[t]{6}{*}{ Ease of use } & Linking requirements to available documents (SRS) & Facility of querying requirement data \\
\hline & $\begin{array}{c}\text { Importing structured requirement document like } \\
\text { excel, XML format }\end{array}$ & $\begin{array}{l}\text { Exporting requirements into standard and easily } \\
\text { updateable format like XML, SQL, JSON }\end{array}$ \\
\hline & $\begin{array}{l}\text { Filtering view of requirements based on different } \\
\text { artefacts (like status, priority) }\end{array}$ & Help facility of how to operate the tool \\
\hline & $\begin{array}{c}\text { Sorting requirements by multiple criteria (ascending } \\
\text { order of version) }\end{array}$ & Searching requirements by keywords within repository \\
\hline & $\begin{array}{l}\text { Exporting requirements into standard and } \\
\text { commercial formats like word, excel, PDF, CSV }\end{array}$ & $\begin{array}{l}\text { Viewing various requirement artefacts and attributes } \\
\text { reports in dashboard }\end{array}$ \\
\hline & $\begin{array}{l}\text { Define custom format for documentation output (e.g. } \\
\text { SRS template facility) }\end{array}$ & $\begin{array}{l}\text { Easily modifiable user interface of tool to add menu, } \\
\text { functions and hot keys }\end{array}$ \\
\hline \multirow[t]{4}{*}{$\begin{array}{l}\text { Requirement } \\
\text { Architecture }\end{array}$} & $\begin{array}{l}\text { Organize requirements by groups (e.g. system, } \\
\text { subsystem, req, sub requirement) }\end{array}$ & $\begin{array}{l}\text { Manage access permissions for requirements to } \\
\text { different users of tool }\end{array}$ \\
\hline & $\begin{array}{l}\text { Define and capture different types of requirement } \\
\text { (FR, NFR, Business req) }\end{array}$ & Define a glossary for a set of requirements. \\
\hline & $\begin{array}{l}\text { Custom format for requirement ID (e.g. for FR } \\
\text { FR001, NFR, NFR002) }\end{array}$ & Linking email to specific requirements \\
\hline & $\begin{array}{l}\text { Provide a template for new projects (e.g., includes } \\
\text { pre-defined requirement types) to minimize setup }\end{array}$ & $\begin{array}{l}\text { Upload and link video/audio files related to } \\
\text { requirements }\end{array}$ \\
\hline \multirow[t]{3}{*}{$\begin{array}{l}\text { Requirement } \\
\text { Management }\end{array}$} & Version control of requirement, baseline creation & $\begin{array}{l}\text { Navigational facility to nested requirement } \\
\text { management }\end{array}$ \\
\hline & $\begin{array}{l}\text { Changing of same attributes to more than } 1 \\
\text { requirement (e.g. changing priority of many } \\
\text { requirements to high) }\end{array}$ & $\begin{array}{c}\text { Generate requirements as list and update fields of any } \\
\text { requirements }\end{array}$ \\
\hline & $\begin{array}{l}\text { Add, Update, delete, search and display of } \\
\text { Primary/Functional Requirements }\end{array}$ & $\begin{array}{c}\text { Edit individual requirements quickly without much } \\
\text { navigation }\end{array}$ \\
\hline \multirow[t]{3}{*}{$\begin{array}{l}\text { Review and } \\
\text { Collaboration }\end{array}$} & $\begin{array}{l}\text { Review the changed requirement and Track } \\
\text { Requirements approval. Notify to respective } \\
\text { stakeholders }\end{array}$ & $\begin{array}{c}\text { Generate report on who is working on which } \\
\text { requirements }\end{array}$ \\
\hline & $\begin{array}{l}\text { Providing review facility of requirements to } \\
\text { customers }\end{array}$ & $\begin{array}{l}\text { List of rejected/approved requirements after review } \\
\text { process }\end{array}$ \\
\hline & $\begin{array}{c}\text { Report on whether a set of requirements have been } \\
\text { reviewed }\end{array}$ & Reusability of requirement for other projects \\
\hline \multirow[t]{3}{*}{$\begin{array}{l}\text { Requirement } \\
\text { Specification }\end{array}$} & Storage of requirement in central repository & $\begin{array}{l}\text { Negotiation with customers before requirements are } \\
\text { specified }\end{array}$ \\
\hline & $\begin{array}{l}\text { Requirements features and artefacts are stored in } \\
\text { database tables }\end{array}$ & $\begin{array}{l}\text { Specification in efficient manner so that it can be } \\
\text { linked to design and code }\end{array}$ \\
\hline & $\begin{array}{l}\text { Any Specification language is used to specify the } \\
\text { requirement, like XML? }\end{array}$ & $\begin{array}{l}\text { The requirements should be specified in a consistent, } \\
\text { accessible and reviewable manner }\end{array}$ \\
\hline \multirow[t]{5}{*}{$\begin{array}{l}\text { Requirement } \\
\text { Modelling }\end{array}$} & $\begin{array}{l}\text { Modelling project functional and non functional } \\
\text { requirements }\end{array}$ & $\begin{array}{l}\text { Model process flows and context diagrams directly in } \\
\text { the tool }\end{array}$ \\
\hline & $\begin{array}{l}\text { Use case modelling with actors and scenario from } \\
\text { collected functional requirements }\end{array}$ & $\begin{array}{c}\text { Textual and Graphical representation of use case } \\
\text { diagram, activity diagram }\end{array}$ \\
\hline & Data modelling of the project (ER modelling) & $\begin{array}{l}\text { Generating diagrams (Use case, activity, sequence) } \\
\text { from written requirements or database }\end{array}$ \\
\hline & Activity and sequences of the requirement & $\begin{array}{l}\text { Modelling use case and converting it into textual } \\
\text { requirements }\end{array}$ \\
\hline & $\begin{array}{c}\text { Requirement Flow Diagram to show the flow } \\
\text { between requirements }\end{array}$ & $\begin{array}{c}\text { Identifying objects from textual requirements to create } \\
\text { class diagrams }\end{array}$ \\
\hline
\end{tabular}




\begin{tabular}{|c|c|c|}
\hline \multirow[t]{2}{*}{ Sub Category } & \multicolumn{2}{|c|}{ Features } \\
\hline & $\begin{array}{l}\text { Association of requirements to UML model with } \\
\text { user interface }\end{array}$ & $\begin{array}{l}\text { Identifying objects from textual requirements to create } \\
\text { Entities within ER diagram }\end{array}$ \\
\hline \multirow[t]{2}{*}{$\begin{array}{l}\text { Design and } \\
\text { Code }\end{array}$} & $\begin{array}{l}\text { Functional Requirement -> Model -> Requirement } \\
\text { flow diagram to help designer }\end{array}$ & Test cases development based on use cases and REQ \\
\hline & Code mapping of requirements & Requirement lifecycle or workflow \\
\hline \multirow[t]{3}{*}{ Other NFR } & \multicolumn{2}{|c|}{ Are non functional attributes are gathered separately? } \\
\hline & \multicolumn{2}{|c|}{$\begin{array}{l}\text { The tool shall collect non functional requirement like availability, portability, scalability, extensibility, } \\
\text { reusability, reliability type of requirements for system at project level }\end{array}$} \\
\hline & \multicolumn{2}{|c|}{ Are NFR properties are related to functional requirement? (Specification of NFR at module level) } \\
\hline \multirow[t]{4}{*}{ Security } & $\begin{array}{c}\text { Does RBAC (Role based access control) is } \\
\text { specified/mentioned at the time of requirement } \\
\text { gathering? }\end{array}$ & $\begin{array}{c}\text { Does tool support confidentiality of requirement by } \\
\text { asking feature of symmetric or asymmetric } \\
\text { encryption algorithm like DES,RC4,AES, Elliptic } \\
\text { Curve }\end{array}$ \\
\hline & $\begin{array}{c}\text { Tool shall support role based Create Read Update } \\
\text { Delete (CRUD) of the requirements (Module } \\
\text { Permissions) }\end{array}$ & $\begin{array}{c}\text { Does tool supports integrity of requirement? Which } \\
\text { requirement should be prevented from unauthorized } \\
\text { modification with techniques like hashing or digital } \\
\text { signature) }\end{array}$ \\
\hline & Ability to provide multiple roles for one user & $\begin{array}{l}\text { Does tool supports the requirement of authentication } \\
\text { for preserving identity of the user by any methods } \\
\text { like biometric, password, smart card, memory card }\end{array}$ \\
\hline & \multicolumn{2}{|c|}{$\begin{array}{l}\text { Does tool supports authorization requirement for allowing only authorized actors to perform CRUD (Create, } \\
\text { Update, Read, Delete) operations on functional requirements }\end{array}$} \\
\hline \multirow[t]{4}{*}{ Privacy } & $\begin{array}{l}\text { Tool shall support the requirement for implementing } \\
\text { pseudonymity for the system (singly proxy method, } \\
\text { onion routing, crowd or any pseudonymizer tool) }\end{array}$ & Does tool supports anonymous user login? \\
\hline & $\begin{array}{c}\text { Does tool supports facility of giving individual or } \\
\text { collective pseudonyms for performing operations on } \\
\text { requirement? }\end{array}$ & $\begin{array}{l}\text { Tool shall support the pseudonym remailers for } \\
\text { hiding the source identity }\end{array}$ \\
\hline & $\begin{array}{l}\text { Does tool supports privacy requirements like privacy } \\
\text { policy management? }\end{array}$ & $\begin{array}{l}\text { Privacy policy questions for framing privacy policy } \\
\text { of the website for the project of type web app or } \\
\text { website }\end{array}$ \\
\hline & \multicolumn{2}{|c|}{$\begin{array}{c}\text { Does tool support unlinkability and unobservability of requirements with facility of spyware detection removal, } \\
\text { browser cleaning eraser, and activity traces eraser? }\end{array}$} \\
\hline
\end{tabular}

\subsubsection{Comparison of "ReqPriSec" with Open}

Source RE tools

The proposed tool is compared based on the matrix designed in the previous section. The various tools are not supporting all the features. The feature support matrix is created in Table 3 for comparison.

Table 3. Feature Support Matrix

\begin{tabular}{|c|c|}
\hline Feature support criteria & Support Level \\
\hline No support by tool & 0 \\
\hline Partial support by tool & 1 \\
\hline Full Support by tool & 2 \\
\hline
\end{tabular}


There are three support values which are used to indicate whether a tool is supporting a specific RE feature or not. There can be the marginal or partial support if the tool is supporting that feature in minimum context. We have taken following open source Requirement Engineering/Management tool for the comparison based on feature matrix. From the available open source tools, these tools are having feature set and development model of the similar kind of the proposed tool.

Table 4. Comparison with Open Source Tools by Feature Support Matrix

\begin{tabular}{|c|c|c|c|c|c|}
\hline Count $\backslash$ Tool & ReqHeap & OSRMT & Rmtoo & Modelio & ReqPriSec \\
\hline No Support & 47 & 58 & 39 & 8 & 16 \\
\hline Partial Support & 36 & 32 & 36 & 25 & 27 \\
\hline Full Support & 30 & 22 & 38 & 80 & 70 \\
\hline
\end{tabular}

The Table 4 list the count points with features supported by tool out of 113 features listed in the feature matrix. The modelio tool is fully supporting 80 features out of 113 features, while OSRMT is having lowest count in the full

\author{
Open Source RE Tools \\ - ReqHeap \\ - OSRMT \\ - Rmtoo \\ - Modelio
}

Comparison of Tool with Support Count Points by Feature Matrix support category. The proposed "ReqPriSec" tool is supporting 70 features which are higher than ReqHeap, OSRMT, Rmtoo tool. It is to be noted that, partial support score for the tool is 27 .

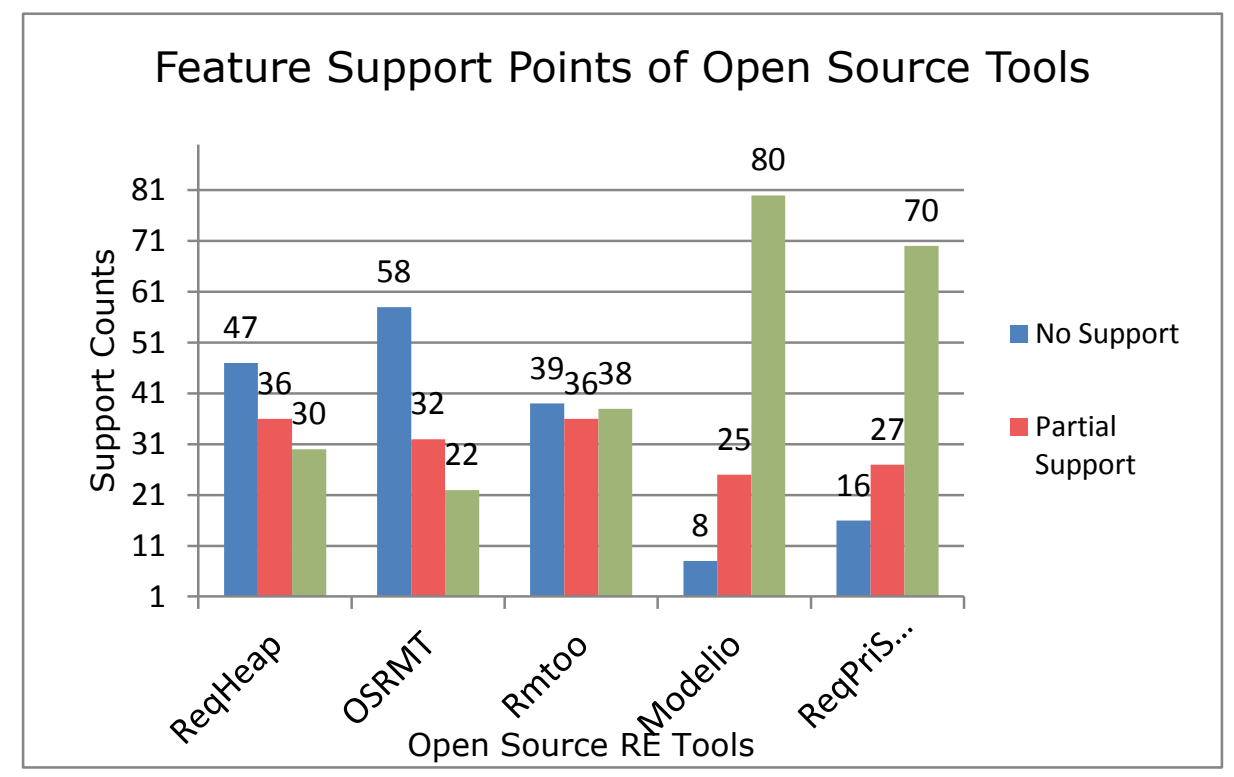

Fig 9: Comparison of ReqPriSec with Open Source Tools for Support Points

The Figure 9 shows the support level of the feature matrix of 113 features designed to evaluate and measure the tools. The modelio tool fully supports 80 features, whereas the proposed tool ReqPriSec supports 70 features. The OSRMT tools scores lower with the full supports of only 22 features, whereas Reqheap web based RE tool supports 30 features. The proposed tool is partially supporting 27 features.

\subsection{Case Study Based Evaluation}

This section present the result of evaluation which is carried out on "ReqPriSec" tool along with four open source RE tools. The tools are tested with novel tool evaluation matrix and evaluated on the basis of four different case studies.

\subsubsection{Design of Tool Evaluation Matrix}

Any tool can be evaluated based on the support and evaluation feature matrix. The functionalities of the tool can be measured with their elicitation and specification support. For evaluation, we have considered following tables and designed the novel matrix for functional requirement, security requirements and privacy requirements of the system. Table 5 shows the support weight based on support criteria.

\section{- $\quad$ Requirement Features Support - RFS}


Table 5. Requirement Feature Support

\begin{tabular}{|l|c|}
\hline Feature Support Criteria & Support Level Weight \\
\hline No support by tool & 1 \\
\hline Partial (marginally) support by tool & 2 \\
\hline Full Support by tool & 3 \\
\hline
\end{tabular}

\section{- $\quad$ Requirements Priority Weight - RPW}

The requirement of the system can have different level priorities. We have considered priority range from 5 to 1 for each requirement of system as shown in Table 6 "RPW"

Table 6. Requirement Priority Weight - RPW

- $\quad$ FR-NFR Weight - FRNFW

\begin{tabular}{|c|c|}
\hline Priority of Requirement & Weight \\
\hline Must have & 5 \\
\hline Higher priority & 4 \\
\hline Nice to have & 3 \\
\hline Lower priority & 2 \\
\hline Not essential & 1 \\
\hline
\end{tabular}

Other matrix is created based on type of requirement as shown in Table 7. The "to do" requirement must have the higher weight than non functional requirement.

Table 7. FR-NFR Weight - FRNFW

\begin{tabular}{|c|c|}
\hline Requirement & Weight \\
\hline Functional Requirement & 2 \\
\hline Non Functional Requirement & 1 \\
\hline
\end{tabular}

To design the Functional, Security and Privacy Requirement Support Score points we have considered basic features except

\section{project and other tool features from feature matrix (Covering} 113 features) designed in the previous section.

(A) Functional Requirement Score Points Formulae

REQVal $=($ RPW $*$ FRNFW $)$

$\boldsymbol{F} \boldsymbol{R e q} \boldsymbol{V}=\sum_{i=1}^{f}$ REQVali $*$ FRFSSi

$\mathrm{f}=$ Number of Functional requirements

FRFSS $=$ Functional Requirement Feature Support Set

FR Score Points (FRSP) $=\sum_{i=1}^{f}$ FReqVi $/ \boldsymbol{f}$

(B) NFR - Security Requirement Score Points Formulae

SecREQVal $=($ RPW $*$ FRNFW $)$

SReqV $=\sum_{i=1}^{S}$ SecREQVali $*$ SFSSi

$\mathrm{s}=$ Number of Security Requirements

SFSS $=$ Non Functional Requirement-Security Feature Support Set

Security Requirement Score Points (SRSP) $=\sum_{i=1}^{S} S R e q V i \quad / \quad s$

(C) NFR - Privacy Requirement Score Points Formulae

PriREQVal $=($ RPW $*$ FRNFW $)$

$\boldsymbol{P R e q V}=\sum_{i=1}^{p}$ PriREQVali $*$ PFSSi

$\mathrm{p}=$ Number of Privacy Requirements

PFSS = Non Functional Requirement-Privacy Feature Support Set 


\section{Privacy Requirement Score Points (PRSP) $=\sum_{i=1}^{S}$ PReqVi $/ p$}

The above matrices are used to evaluate and compare the open source tools with proposed tool "ReqPriSec" with different case studies. For security and privacy the sub categories like confidentiality, anonymity, authorization etc. are also considered in the feature support set.

\subsubsection{Evaluation of Tools with Case Study}

To evaluate and compare "ReqPriSec" with open source tools, we have tested the tools based on different matrices for requirements of case study E-voting system. The system is mapped with functional and non functional requirement specifically with security and privacy properties.

- Online E-Voting system [15] [16]
We have considered there major categories: Functional requirements, Security requirement and Privacy requirements. The testing results and evaluation are described in following section.

\section{E-Voting System}

The case study is based on E-voting system which is dealing with operation of voting through electronic system. The sample Functional requirements, Security and Privacy requirement are shown in Table 8 to Table 10 .

\subsubsection{Functional, Security and Privacy Requirements}

Table 8. Sample Functional Requirements of E-Voting System

\begin{tabular}{|c|c|}
\hline No. & Key Functional requirements \\
\hline R1 & Voter Registration \\
\hline R2 & Counting mechanism of voting \\
\hline R3 & Ballot Generation \\
\hline R4 & Warning and alert for time of voting \\
\hline R5 & Recounting facility in case of problem \\
\hline R6 & All valid votes are counted correctly \\
\hline R7 & Voters can vote from anywhere with stipulated time \\
\hline R8 & Voter should complete the voting process successfully \\
\hline R9 & The image, symbol and other detail of the candidate should be retrieved properly (Display \\
\hline R10 & Profile setting of voter, election officials, operator \\
\hline R11 & Calculate voting result \\
\hline R12 & Manage parties and candidate list \\
\hline R13 & Election set up and closing process \\
\hline R14 & Evaluation of election result by system by predefined rules \\
\hline R15 & Mution rules for win with percentage of votes \\
\hline
\end{tabular}

Table 9. Sample Security Requirements of E-Voting System

\begin{tabular}{|c|c|}
\hline No. & Security Requirements \\
\hline SR1 & Role based Access control for CRUD operations for voting process \\
\hline SR2 & Careful control on unauthorized access of voting data \\
\hline SR3 & Nontrivial authentication mechanism for operator, admin \\
\hline SR4 & Accessing voting data, result by advance biometrics or other multiphase authentication \\
\hline SR5 & Controlled access for voter, operator, admin to perform any activity in voting system \\
\hline SR6 & Hiding voter's vote from any voter, operator, candidate \\
\hline
\end{tabular}




\begin{tabular}{|c|c|}
\hline No. & Security Requirements \\
\hline SR7 & Prevention of accidental or malicious use of Election data \\
\hline SR8 & Use of encryption technique to open voting phase \\
\hline SR9 & All internal operations must be monitored, without violating voter confidentiality \\
\hline SR10 & Verification of result by authorized actor (preserving integrity) \\
\hline SR11 & Prevention of violation of system integrity \\
\hline SR12 & techniques \\
\hline SR13 & $\begin{array}{r}\text { Protecting result can count till the result is declared from external interfaces, trapdoors and other } \\
\text { SR14 }\end{array}$ \\
\hline SR15 & Preserving voter demographic, religion, personal detail \\
\hline
\end{tabular}

Table 10. Sample Privacy Requirements of E-Voting System

\begin{tabular}{|c|c|}
\hline No. & Privacy Requirements \\
\hline PR1 & Disclosing voter privacy through permitted identification \\
\hline PR2 & Preserving voter list, privacy of result sheet for different election \\
\hline PR3 & Managing personal records, demographic, religion, cast and other detail of voter \\
\hline PR4 & $\begin{array}{c}\text { Three levels of identity privacy preservation while preserving voter's identity and allowing } \\
\text { authorized user to access }\end{array}$ \\
\hline PR5 & Preserving privacy of vendor, candidate and other party detail \\
\hline PR6 & Voter anonymity through masking the identity of voter \\
\hline PR7 & $\begin{array}{l}\text { The association between recorded votes and the identity of the voter must be completely } \\
\text { unknown within system (Anonymity) }\end{array}$ \\
\hline PR8 & $\begin{array}{l}\text { A system of identifying voters between entities must exist for interoperability to preserve the } \\
\text { privacy, however it is for extracting detail of voter }\end{array}$ \\
\hline PR9 & $\begin{array}{c}\text { Maintaining voter's anonymity through use of coded voter identifiers (pseudonyms) in at some } \\
\text { parts of voting process }\end{array}$ \\
\hline PR10 & Federated pseudonym identifier for voter \\
\hline PR11 & No linkages between one voter to other voter \\
\hline PR12 & Voter should not observe other voter's detail \\
\hline PR13 & No observation from the history of the previous election to predict voter's vote \\
\hline PR14 & Privacy policy for non disclosure to other than government or national level institute \\
\hline PR15 & Acceptance from voter related to privacy policy of the system \\
\hline
\end{tabular}


After applying tool evaluation matrix on above 3 categories of requirements, testing result has generated following score points table. If all the requirements are supported fully by the tool then full support value points are generated with different tool's score points.

Table 11. E-Voting System Score Points

\begin{tabular}{|c|c|c|c|c|}
\hline Tool Name & FR Score & $\begin{array}{c}\text { NFR-Security } \\
\text { Score }\end{array}$ & $\begin{array}{c}\text { NFR-Privacy } \\
\text { Score }\end{array}$ & $\begin{array}{c}\text { Security and } \\
\text { Privacy Score }\end{array}$ \\
\hline ReqHeap & 1042.50 & 8.33 & 6.96 & 16.29 \\
\hline OSRMT & 940.65 & 7.65 & 5.00 & 12.65 \\
\hline Rmtoo & 1132.50 & 9.04 & 5.35 & 18.28 \\
\hline Modelio & 1425.00 & 12.13 & 8.17 & 14.39 \\
\hline ReqPriSec & 1365.00 & 14.46 & 12.35 & 26.81 \\
\hline FULL SUPPORT VALUE & 1687.50 & 15.71 & 13.30 & 29.01 \\
\hline
\end{tabular}

\subsubsection{Functional Requirement Support for E-}

\section{Voting system}

Figure 10 shows the functional requirement support in percentage for proposed tool ReqPriSec and other 4 open source tools. The modelio tool is having 84.4 percentage support and highest in the chart for supporting features related to functional requirements. The proposed tool has 80.9 percentage score in this category which is almost near to modelio tool.

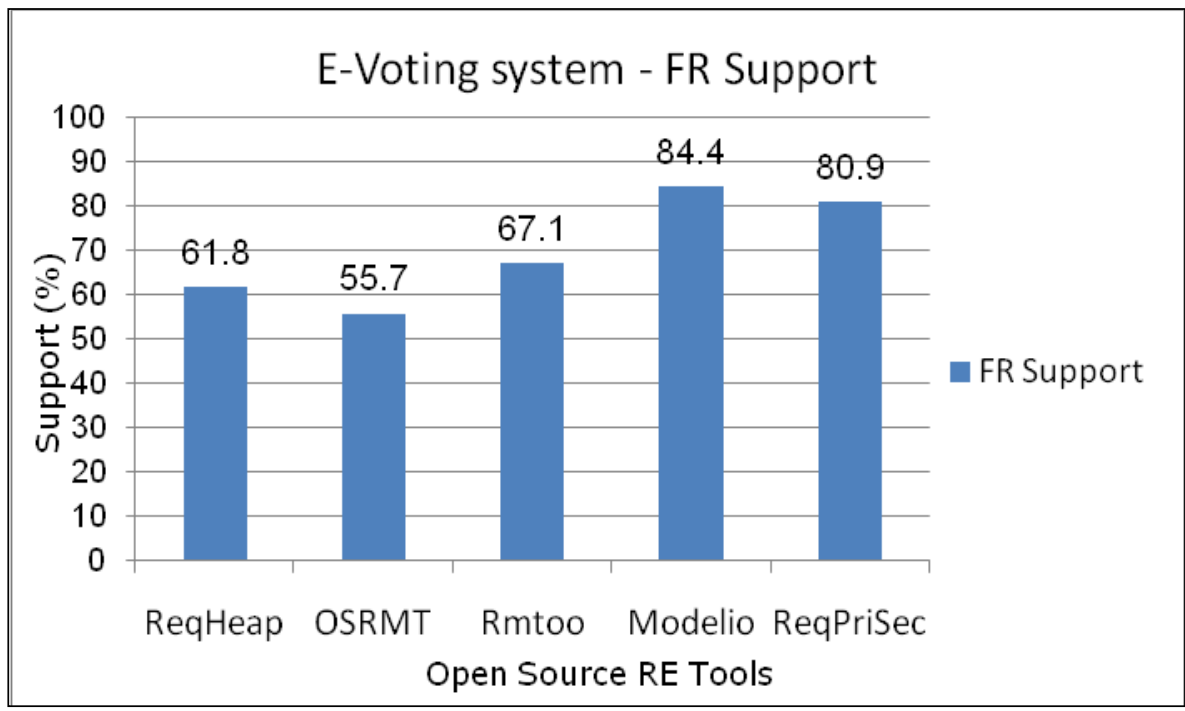

Fig 10: Functional Requirement Support for E-Voting System

\subsubsection{Security Requirement Support of E-voting system}

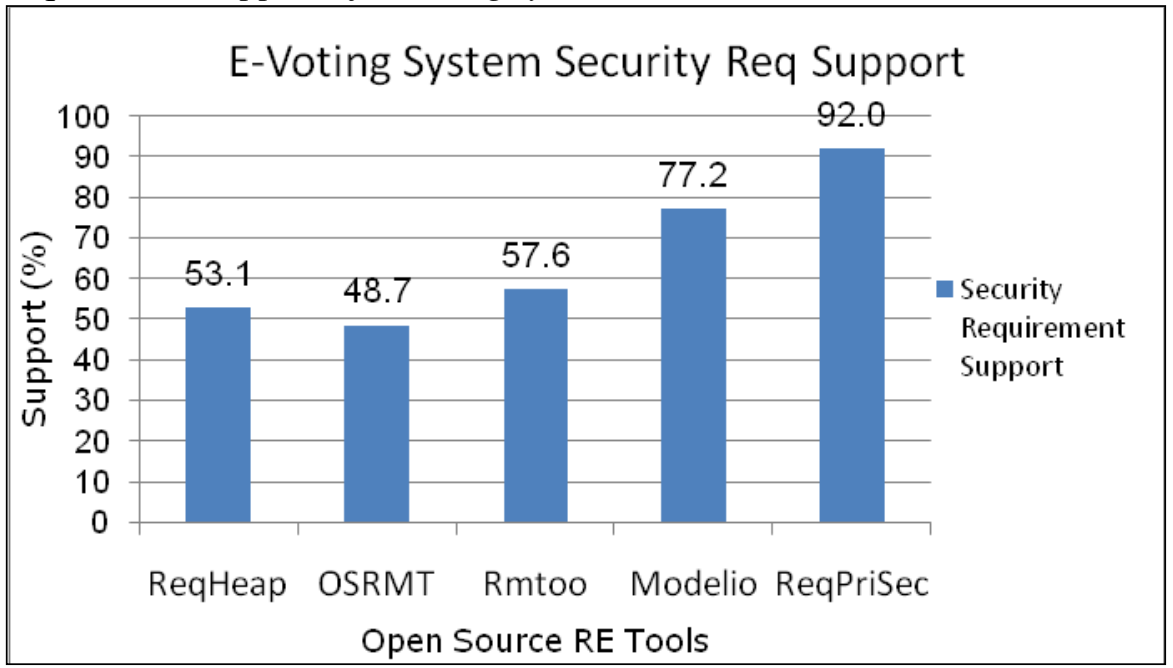

Fig 11: Security Requirement Support for E-Voting System 
The proposed tool is scoring $92 \%$ in the favour of security requirements as shown in Figure 11. Modelio tool is supporting $77.2 \%$ security requirements. However other tools are having very low score and it is less than $60 \%$.

\subsubsection{Privacy Requirement Support of E-voting system}

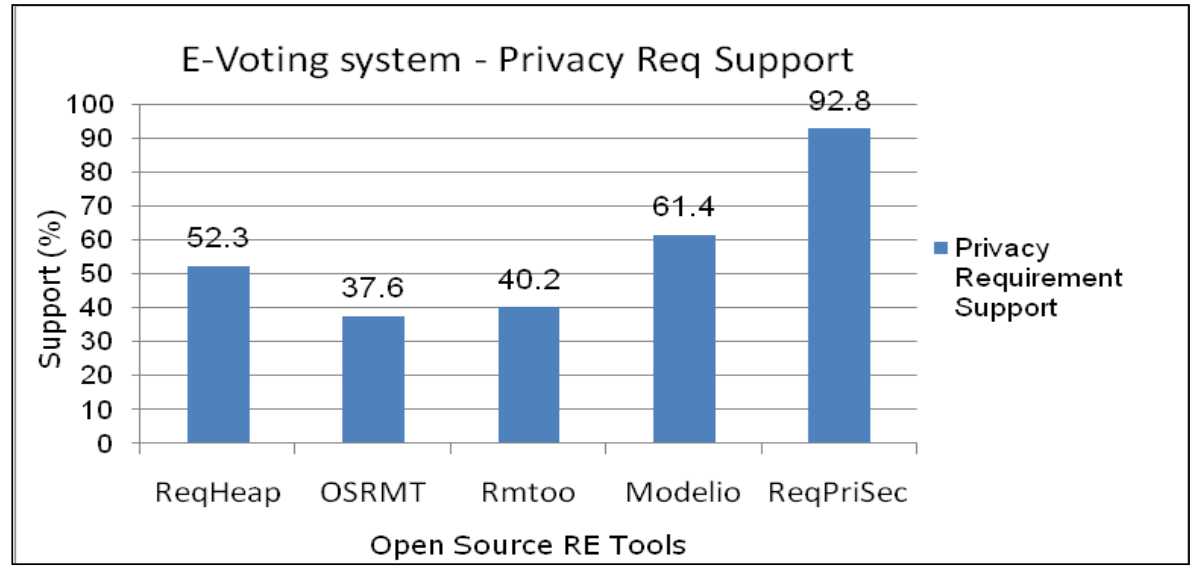

Fig 12: Privacy Requirement Support for E-Voting System

As compared to other open source tools, the ReqPriSec is achieving 92.8\% support, which is highest and there is a significant difference between modelio tool's $61.4 \%$ as shown in Figure 12. The OSRMT has merely only 37.6 percentage support for this category.

\section{CONCLUSION}

In this paper, we have proposed the RE tool to overcome the challenges of incomplete, inconsistent and ambiguous requirement elicitation and specification. The major non functional requirement like security and privacy are considered in the tool development. The tool is evaluated based on uniquely designed 113 features for different RE categories. The proposed "ReqPriSec" tool is having more than $90 \%$ support in security and privacy requirements as compared to the analysed open source tools. The tools is having unique features like efficient elicitation interface, linkages of security and privacy requirements, narrative use case representation, project and requirement hierarchy, requirement artefacts management and many more. The support of web services and NLP shall be implemented in future to enhance this tool.

\section{REFERENCES}

[1] D. Firesmith, "Quality Requirements Checklist," Journal of Object and Technology, vol. 4, no. 9, pp. 31-38, 2005.

[2] The Standish Group, "The Standish CHAOS Report 2014," 2014.

[3] M. Jørgensen and K. Moløkken, "How Large Are Software Cost Overruns?",A Review of the 1994 CHAOS Report."

[4] H. Meth, M. Brhel, and A. Maedche, "The state of the art in automated requirements elicitation," Information and Software Technology, vol. 55, no. 10, pp. 16951709, Oct. 2013.

[5] B. H. C. Cheng and J. M. Atlee, "Research Directions in Requirements Engineering", Future of Software Engineering (FOSE '07), 2007, pp. 285-303.

[6] D. Firesmith, "Modern Requirements Specification" JOURNAL OF OBJECT TECHNOLOGY, vol. 2, no. 1, pp. 53-64, 2003.

[7] J. M. Carrillo de Gea, J. Nicolás, J. L. F. Alemán, A. Toval, C. Ebert, and A. Vizcaíno, "Requirements
Engineering Tools," IEEE Software, vol. 28, no. 4, pp. 86-91, Jul. 2011.

[8] "ISO/IEC TR 24766:2009, Information technology Systesm and software engineering - Guide for requirements engineering tool capabilities," Geneva, Switzerland, 2009.

[9] J. M. Carrillo de Gea, J. Nicolás, J. L. Fernández Alemán, A. Toval, C. Ebert, and A. Vizcaíno, "Requirements engineering tools: Capabilities, survey and assessment," Information and Software Technology, vol. 54, no. 10, pp. 1142-1157, Oct. 2012.

[10] "Requirement Heap download | SourceForge.net." [Online]. Available: https://sourceforge.net/projects/reqheap/. [Accessed: 19Apr-2019].

[11] "rmToo - Free and Open Source Requirements Management Tool." [Online]. Available: http://rmtoo.florath.net/. [Accessed: 16-Apr-2019].

[12] "Open Source Requirements Management Tool download | SourceForge.net." [Online]. Available: https://sourceforge.net/projects/osrmt/. [Accessed: 19Mar-2019].

[13] "Modelio Open Source - UML and BPMN free modeling tool." [Online]. Available: https://www.modelio.org/. [Accessed: 20-Apr-2019].

[14] R. Alexandrian et al., "Requirements Management Tool Evaluation Report," 2016.

[15] "Weblet Importer." [Online]. Available: https://www.coe.int/t/dgap/goodgovernance/activities/evoting/work_of_evoting_committee/03_background_doc uments/92IP1(2002)23_en.asp. [Accessed: 24-Feb2019].

[16] "Voting System Standards, Testing and Certification." [Online].Availablehttp://www.ncsl.org/research/elections -and-campaigns/voting-system-standards-testing-andcertification.aspx. [Accessed: 24-Apr-2019]. 